\title{
Hedef Programlama Yaklaşımı İle Temizlik Personeli Çizelgeleme Problemi İçin Bir Model Önerisi
}

\author{
Emir Hüseyin ÖZDER ${ }^{1}$, Emre VARLI $^{2}$, Tamer EREN $^{3 *}$ \\ ${ }^{1}$ Başkent Üniversitesi, Ticari Bilimler Fakültesi, Yönetim Bilişim Sistemleri Bölümü, 06790, Ankara, Türkiye \\ ${ }^{2,3}$ Kırıkkale Üniversitesi, Mühendislik Fakültesi, Endüstri Mühendisliği Bölümü, 71450, Kırıkkale, Türkiye
}

*Sorumlu Yazar: tamereren@gmail.com

Geliş Tarihi: 08.10.2017

Kabul Tarihi: 12.12 .2017

\section{Özet}

Kamu sektöründe temizlik personellerinin doğru ve uygun çalıştırılması önemli problemlerden biridir. Temizlik personelinin en uygun görev yerlerine atanması ile temizlik hizmetinin en iyi şekilde verilmesi sağlanabilir. Bu çalışmada personelin, temizlik yapılacak en uygun yerlere atanması problemi ele alınmıştır. Uygulama yeri olarak 7 katlı, 58 odalı, yirmi dört saat hizmet veren bir üniversite hastanesi ele alınmıştır. Toplamda 70 temizlik personelinin bir aylık çizelgeleneceği problem için hedef programlama modeli kurulmuştur. Kurulan matematiksel modelin çözümünde ILOG CPLEX Studio IDE Optimizasyon programı kullanılmıştır. Matematiksel model ile amaçlanan hedefler gerçekleştirilmiş ve mevcut çizelgeden daha iyi sonuçlar elde edildiği gösterilmiştir.

Anahtar kelimeler: Temizlik personeli çizelgeleme, Personel atama, Hedef programlama

\section{A Model Suggestion for Cleaning Staff Scheduling Problem with Goal Programming Approach}

\begin{abstract}
The proper operation of cleaning personnel is one of the major problems in public institutions. By assigning the cleaning personnel to the most appropriate duty areas, cleaning service can be provided in the best conceivable way. In this study, the problem of assigning the cleaning personnel is discussed to the most appropriate places to clean. As a place of application, a university hospital was dealt with which is serving 24 hours with a total of 58 rooms. A goal programming model has been established for the problem that a total of 70 cleaning personnel will be scheduled for a month. ILOG CPLEX Studio IDE Optimization program was used to solve the mathematical model. The mathematical model has shown that the intended goals are achieved, and better results are obtained from the existing schedule.
\end{abstract}

Keywords: Cleaning staff scheduling, Personnel assignment, Goal programming 


\section{Giriş}

Çizelgeleme problemleri, son yıllarda araştırmacılar tarafından oldukça fazla incelenen problem türlerinden biri halini almıştır (Bergh vd., 2013). Çizelgeleme problemlerinin spesifik bir türü olan Personel Çizelgeme problemleri, bugüne kadar yapılan çizelgeleme çalışmaları incelendiğinde, üzerinde en çok çalışılan çizelgeleme problemlerinden biri olarak karşımıza çıkmaktadır (Bergh vd., 2013).

Personel çizelgeleme problemi sanayilerde, işletmelerde, hastanelerde ve buna benzer pek çok yerde karşılaşılan önemli bir çizelgeleme problemdir. Problemin çözümündeki asıl amaç, çalışan personelin gerekli yerlere adaletli ve dengeli bir şekilde dağıtarak daha iyi bir hizmet vermesi ve daha adil koşullarda çalışmalarının sağlanmasıdır. Bu probleme olan ilginin ve dikkatin artması işletmelerin ekonomik faktörler tarafından motive edilebilir bir hal almasını sağlamıştır. Şirketlerde emek maliyeti, doğrudan doğruya maliyet bileşenidir. Yeni bir personel programı uygulayarak bu maliyeti belli bir oranda kısaltmak ve maliyetleri düşürmek açısından önemlidir. İşletmelerde çalışan personelin verim ve kalitesinin arttırmasına yönelik çalışmalar yapılması, personel çizelgeleme probleminin çözüme kavuşturulması adına gereklidir. Ayrıca personel memnuniyetinin arttırılmasında personel çizelgelemenin önemi oldukça fazladır. Çünkü personel çizelgeleme, çalışan personelin ihtiyaç ve tercihlerini göz ardı etmeden bir model oluşturarak hem çalışan personelin hem de ilgili işletmenin planlı ve sistemli bir şekilde idame etmesini sağlamaktadır.

Personel çizelgeleme problemlerinde optimum sonuçlar için en çok matematiksel programlama modelleri kullanılmaktadır (Bergh vd., 2013). Matematiksel modeller içinde de birçok amacın aynı anda veya hiyerarşik sırayla optimize edildiği hedef programlama ile yapılan birçok çalışma mevcuttur. Hedef programlama her bir amacı birer kısıt haline dönüştürür, kısıtları önem sıralamasına göre dizer ve bu kısıtların amaçlardan sapmasını minimize ederek hedefe ulaşmaya çalışır (Tamiz ve Jones, 1997).

$\mathrm{Bu}$ çalışmada, hedef programlama yöntemi kullanılarak, bir üniversite hastanesinde temizlik görevinde yer alan personel için bir aylık çizelgeleme önerilmiştir. Hastanede 7 katta toplam 58 oda mevcuttur. Kurulan modelde çalışanların kıdem derecelerine göre belirli yerlere atanma zorunluluğu dikkate alınmıştır. Çalışmada 5 farklı kıdem derecesine sahip çalışan sınıflandırması bulunmaktadır. Personel atamasında birtakım hedeflere ulaşılmak istenmektedir. Ulaşılmak istenen hedefler; (i) 5. kıdeme sahip personelin görev sayısı, (ii) ilk üç kıdeme sahip personelin görev sayısı, (iii) tecrübeli personellere, üst kıdeme sahip kişilerin kullandığı odaların temizlenmesidir.

$\mathrm{Bu}$ çalışmanın İkinci Bölümünde personel çizelgeleme problemi anlatılmıştır. Üçüncü Bölümde, kullanılan hedef programlama yöntemi hakkında bilgi verilmiştir. Dördüncü Bölümde personel çizelgeleme konusunda literatürde yapılan çalışmalardan bahsedilmiştir. Beşinci Bölümde 
hastanede örnek uygulama yapılmıştır. Çalışmanın son bölümünde ise sonuçlar ve öneriler ifade edilmiştir.

\section{Personel Çizelgeleme}

Günümüzde bahsedilen mevcut personel çizelgeleme problemleri 1950’lerde Dantzig (1954) ve Edie'nin (1954) ortaya attı̆ğ problem yapısından farklılık göstermektedir. Bu dönemlerde bahsedilen çizelgelemeler sadece personel isteklerinin karşılanmasını sağlayan ya da gereken işçi sayısı kadar atama yapılmasından ibaret olan çalışmalardır. Ancak günümüzde; personel isteklerinin karışlanması ve tatmin edici bir çizelgeleme kararının verilmesi gereği hâsıl olmuştur. Literatürde özel personel çizelgeleme modelleri mevcuttur. Örneğin: Esnek talebe göre oluşturulmuş modeller, çalışılan yerin değiştirildiği durumlara göre modeller ve kısıtlanmış görev değişikliği olan modeller bunlara örnektir. Özel oluşturulan bir diğer örnek model olan hemşire çizelgeleme, yıllardan beri üzerinde çalışılan hem sezgisel algoritmalarla hem de kesin metotlarla çözülen bir çizelgeleme problemidir. Ancak, belirli algoritmik çözümler ve modeller olsa da literatürde genel olarak kullanılan kalıplaşmış bir personel çizelgeleme modeli bulunmamaktadır.

Çizelgelemeler oluşturulurken firmalar, işçilerin istek ve tercihlerini (belirli vardiyada çalışma, belirli kişi ile çalışma, belirli izin günü vs.) karşılayabilmek adına, yarı zamanlı işe alma ya da esnek çalışma saatleri gibi birtakım yöntemleri önermektedirler. Personel çizelgeleme, üzerinde uzun uğraşlar ve vakit harcanması gereken bir iştir. Çizelgeleme işi yapılırken, birçok kısıt ile personelin ve hizmet alanların tamamının hoşnut olmasının istenmesi, problemi daha da çözümü zor bir hale getirmektedir. Personel çizelgelemedeki ana hedef; kaynakların verimli kullanılmasını sağlayarak, dengeli iş yükü dağılımı yapmak ve mümkün olduğunca bireysel istekleri karşılamaktır. İyi bir çizelgenin, bünyesinde adaletli görev dağılımı, karşılanmış personel istekleri ve verimli kaynak kullanımını barındırması beklenmektedir. Bergh vd. 'nin (2013) çalışmalarında bahsedildiği üzere, çizelgeleme problemlerinin önceki çalışmalarına bakıldığında genellikle personel isteklerinin ikinci plana itildiği görülmektedir (Edie, 1954; Dantzig, 1954). Fakat bu durum gitgide değişmiştir ve personel istekleri çizelgeleme problemlerinde önemli bir yer edinmiştir.

\section{Hedef Programlama}

Amaca ulaşmak için alınması gereken kararların birçoğunu yapısında da çok amaçlılık yatabilir. Amaçların bazıları birbirleriyle benzerlik gösterse de bazıları birbirleriyle çelişebilir. $\mathrm{Bu}$ tarz durumlarda hedeflerin aynı zamanda sağlanabilmesi için birden fazla amaca hizmet eden programlama modelleri kullanılmaktadır. Bu modellerden birisi de Hedef Programlamadır. Hedef 
programlama çok amaçlı karar verme problemlerinin çözümünde yaygın olarak kullanılan bir tekniktir. Hedef Programlama her bir amacı birer kısıt haline dönüştürür, kısıtları önem sıralamasına göre dizer ve bu kısıtların amaçlardan sapmasını minimize ederek hedefe ulaşmaya çalışır (Tamiz ve Jones, 1997).

Hedef programlamada amaç kriterinin doğrudan maksimizasyonu veya minimizasyonu yapılmaz, bunun yerine hedefler arasındaki sapmalar minimize hale getirilmeye çalışılır. Doğrusal programlamada oluşan bu gibi sapmalar “Aylak Değişkenler” olarak isimlendirilirken, hedef programlamada bu sapmalar yeni bir mana kazanırlar. Sapan değişkenler pozitif ve negatif yönde sapmalar şeklinde iki boyutta gösterilir. Amaç fonksiyonu ise yalnızca bu sapan değişkenlerden kurulur (Özder, 2015).

\subsection{Değişkenler ve Genel Gösterim}

$\begin{array}{ll}x_{j}: j . \text { Karar değişkeni } & \forall j \\ a_{i j}: \text { i. hedefin j. karar değişkeni katsayısı } & \forall i v e \forall j \\ b_{i}: \text { i. hedef için ulaşılmak istenen değer } & \forall i \\ d_{i}{ }^{+}: i . \text { hedefin pozitif sapma değişkeni } & \forall i \\ d_{i}: i . \text { hedefin negatif sapma değişkeni } & \forall i\end{array}$

Genel gösterim ise şu şekildedir (Charnes ve Cooper, 1977):

Minimize $\mathrm{Z}=\sum_{i=1}^{m}\left(d_{i}^{+}+d_{i}^{-}\right)$

$\sum_{j=1}^{n} a_{i j} x_{j}+d_{i}^{+}+d_{i}^{-}=b_{i}$,

$d_{i}^{+*} d_{i}^{-}=0$,

$\forall i$

$x_{j}, d i^{+}, d_{i}^{-}>=0$

$\forall i$

$\forall i, j$

Aynı anda hem pozitif hem de negatif sapma oluşamayacağından dolayı sapan değişkenlerin en az bir tanesinin ya da ikisinin de sıfıra eşit olması gerekmektedir. İstenmeyen sapan değişkenlerin oluşturulmasından hemen sonra hedef programlama formülasyonu kurulur. Tüm bu değişkenler içerisinden sadece bir tanesi karar verici tarafından minimize yapılmak istenmektedir (Tamiz vd., 1999; Romero, 2001). 


\section{Literatürde Yapılan Çalışmalar}

Literatürde personel çizelgeleme ile ilgili birçok çalışma bulunmaktadır. Bard vd. (2003) çalışmalarında Birleşik Devletlerin posta servisinde tur çizelgeleme problemini ele almışlardır $\mathrm{Bu}$ problemi tamsayılı bir doğrusal model yardımı ile dile getirmişlerdir. Corominas vd. (2004), çalışmalarında karışık tam sayılı programlama modeli kullanarak, işgücü dengeleme ve düzenleme gibi problemler üzerinde çalışmışlardır. Ernst vd. (2004) çalışmalarında personel çizelgeleme problemleri ile ilgili literatüre büyük katkı sağlayan bibliyografik bir çalışma yapmışlardır. Çalışmalarında çözüm yöntemlerinden bahsetmişlerdir. Azaiez ve Al-Sharif (2005) çalışmalarında 01 hedef programlama yöntemi kullanarak hemşire çizelgeleme problemini çözüme kavuşturmuşlardır. Yazarlar, çalışma sonunda daha önce el ile yapılan çizelgeleme sonuçlarından daha iyi sonuçlar elde etmişlerdir. Güneş vd. (2005) nöbet çizelgeleme problemi üzerine çalışmışlardır. Yunes vd. (2005) çalışmalarında hibrit bir algoritma ile tam sayılı programlama yöntemlerini kullanarak bir firma için personel planlanması konusunu ele almışlardır. Topaloğlu (2006) çalışmasında hedef programlama yöntemi ile sağlık personeli çizelgeleme problemini ele almıştır. Trilling vd. (2006) çalışmalarında hastanede hemşire çizelgeleme sorunu üzerine çalışmışlardır. Lezaun vd. (2006) çalışmalarında metro hattında çalışan işçilerin işgücü çizelgelemelerini yapmışlardır. Chu (2007) çalışmasında hedef programlama tekniği kullanarak bir havaalanındaki personelin çizelgeleme problemini çözüme kavuşturmuştur. Lezaun vd. (2007) bir diğer çalışmasında, demiryolu sürücülerinin işgücü çizelgelemesi çalışmışlardır. Corominas vd. (2007), çalışmalarında üretim işçilerinin vardiya çizelgelemesini yaparak ve üretim planlama sorununu ortadan kaldırmayı amaçlamışlardır. Thompson ve Pullman (2007) çalışmalarında personel vardiya çizelgeleme problemini çözüme kavuşturmuşlardır. Sinreich ve Jabali (2007) çalışmalarında vardiya çizelgeleme problemini çözüme kavuştururken, doğrusal programlama modelini ve simülasyon araçlarını kullanmışlardır. Horn vd. (2007) çalışmalarında mürettebat çizelgeleme problemini incelemişlerdir. Çalışmayı Avustralya ülkesinin kraliyet güçlerinin ellerinde bulundurdukları savunma mürettebatının üzerinde yapmışlardır ve başarılı sonuçlar elde ettikleri görülmüştür. Çetin vd. (2008) tamsayılı programlama yöntemini de dâhil ederek uçuş ekibi çizelgelemesi yapmışlardır. Sungur (2008) çalışmasında karma tamsayılı programlama ile tur çizelgeleme problemini çözüme kavuşturmuştur. De Matta ve Peters (2009), şehirlerarası taşımada iş çizelgeleme konusunda çalışma yapmışlardır. Tsai ve Li (2009) çalışmalarında hemşire çizelgeleme problemini ele almışlardır. Lezaun vd. (2010) çalışmalarında demiryolu çalışanları için bir vardiya çizelgeleme problemi üzerine çalışmışlardır. Rönnberg ve Larsson (2010) İsveç sağlık sektöründe çalışan hemşirelerin atama problemi hakkında çalışmışlardır. Zolfaghari vd. (2010) çalışmalarında personel çizelgeleme problemini ele almışlardır. Fırat ve Hurkens (2011) karışık tamsayılı 
programlama ile personel çizelgelemesi yapmışlardır. Bağ vd. (2011) çalışmalarında 0-1 hedef programlama ve analitik ă̆ prosesi yöntemini kullanarak hemşire çizelgeleme problemini incelemişlerdir. Hung-Tso vd. (2012) çalışmalarında hedef programlama tekniği ile personel çizelgeleme problemini incelemişlerdir. Li vd. (2012) hedef programlama yöntemi ile sezgisel yöntemleri birlikte kullanarak personel çizelgelemesi yapmışlardır. Bektur ve Hasgül (2013) hedef programlama yöntemi kullanarak personel çizelgeleme problemiyle ilgili örnek olay çalışması yapmışlardır. Bergh vd. (2013) çalışmalarında personel çizelgeleme problemleri ile ilgili bibliyografik bir çalışma yapmışlardır. Yazarlar çalışmada, öncesinde yapılan araştırma makalelerini inceleyerek sınıflandırma oluşturmuşlardır ve kendi inceledikleri makaleleri bu sınıflandırmaya göre yeniden düzenlemişlerdir. Kassa ve Tizazu (2013) personel ataması üzerine çalışma yapmışlardır. Louly (2013) çalışmasında bir telekomünikasyon merkezinde vardiya çizelgeleme problemini hedef programlama yöntemi ile çözmüştür. Labadi vd. (2014) çalışmalarında personel çizelgele problemini gidermek için çok amaçlı hedef programlama kullanmışlardır. Öztürkoğlu ve Çalışan (2014) çalışmalarında farklı personel isteklerini de bünyesinde barındıran bir hemşire çizelgeleme problemini ele almışlardır. Todovic vd. (2015) çalışmalarında hedef programlama yöntemi ile polis memurları için bir çizelgeleme yapmışlardır. Ünal ve Eren (2016), nöbet çizelgeleme konusunda çalışmışlardır. Varlı vd. (2016) çalışmalarında bir metroda çalışan vatmanların gerekli hizmeti karşılamak adına aylık işgücü planının yapılması konusunda bir model önermişlerdir. Önerilen modelin verdiği sonuçların, mevcut duruma göre daha iyi olduğunu göstermişlerdir. Şahiner vd., (2017) hemşire çizelgeleme problemi için yeni bir model önerisinde bulunmuşlardır. Önerdikleri modele göre elde edilen sonuçların daha verimli olduğunu söylemişlerdir. Ciritoğlu vd., (2017) çalışmalarında Kırıkkale Üniversitesinde çalışmakta olan güvenlik görevlilerinin günlük atandıkları vardiyaların adaletli ve dengeli bir biçimde hazırlanması amaçlamışlardır. Varlı ve Eren (2017) çalışmalarında, tüm gün hizmet veren Kırıkkale'deki bir hastanenin yoğun bakım, ameliyathane ve acil bölümlerine, hastanenin her vardiyada ihtiyaç duyduğu hemşire sayısını karşılamak için bir hedef programlama modeli önermişlerdir. Varlı vd., (2017) çalışmalarında bir hastanede çalışan hemşirelerin özel izin isteklerini dikkate alarak aylık çalışma planlarının en iyi şekilde yapılması için bir hedef programlama modeli geliştirilmiştir.

\section{Uygulama}

Bu çalışma, yirmi dört saat çalışan bir üniversite hastanesi binasında bulunan odaları detaylı olarak temizleyecek personelin çizelgelenmesini kapsamaktadır. Odaların bazılarının sabah ve öğle saatlerinde meşgul ve kalabalık olması sebebiyle sadece gece vardiyasında detaylı olarak temizlenmesi gerekmektedir. Ayrıca, yine odaların bir kısmının sabah ve öğle saatlerinde üst düzey 
yöneticiler tarafından aktif olarak kullanılması sebebiyle temizlik yapılması için gece vardiyasının seçilmesi gerekliliği bildirilmiştir. Çalışmayı diğer personel çizelgeleme problemlerinden ayıran özelliklerden birisi de problem boyutunun farklı olması ve diğer çizelgeleme problemlerinde görülmeyen özel kısıtlar barındırmasıdır. Temizlik yapılması için atanan personelin odaları temizlemekten başka yapmaları gereken işler de mevcuttur. Vardiyalarda işbaşı yapan personelin odaları temizlemesi yaklaşık olarak 4 saat sürmektedir. Çalışanların odaları temizlemeleri için yapılan atamalar, sadece kendi vardiyaları dâhilinde temizlemeleri gereken odalardan oluşmaktadır. Odaları temizleyecek personellerin birbirinden farklı beş çeşit dereceleri vardır. Bu dereceler çalışanların, kurumdaki çalışma sürelerine göre verilen derecelerdir. Birinci, İkinci ve Üçüncü Derece çalışanlar, bulundukları kurumda 3 yıldan az süredir çalışan personellerdir. Genellikle çok tecrübeye sahip olmayan bu personellerin üst düzey yöneticilerin odaları yerine başka odaları temizlemeleri istenmektedir. Dördüncü Dereceye sahip personeller 4 ile 7 yıl arası tecrübeye sahip personellerdir. 8 yıl ve üzeri sürede çalışan personeller Beşinci Derece grubu oluşturmaktadır. Bu personeller, tüm üst düzey yöneticilerin ve diğerlerine oranla daha önemli kullanım alanına sahip mekânların temizliklerinden sorumlu olan personelleri kapsamaktadır. Bu problem ile ilgili veriler Tablo 1'de verilmiştir.

Tablo 1. Problemin Verileri

\begin{tabular}{ccccc}
\hline $\begin{array}{c}\text { Personel } \\
\text { Kıdem } \\
\text { Derecesi }\end{array}$ & $\begin{array}{c}\text { Haftalık İzin } \\
\text { Günü Sayısı }\end{array}$ & $\begin{array}{c}\text { Vardiya Yapılması İstenen } \\
\text { Zaman Dilimi }\end{array}$ & $\begin{array}{c}\text { Çalışması Gerekli } \\
\text { Gün Sayısı }\end{array}$ & Personel Sayısı \\
\hline 1 & 1 & Sabah - Öğle & 26 & 14 \\
2 & 1 & Sabah - Öğle & 26 & 15 \\
3 & 1 & Sabah - Öğle & 26 & 15 \\
4 & 1 & Gece & 25 & 15 \\
5 & 2 & Gece & 23 & 11 \\
\hline
\end{tabular}

\subsection{Matematiksel Model}

Çizelgeleme probleminin çözümü için oluşturulan matematiksel modelin basamakları bundan sonraki bölümde detaylı olarak verilmiştir.

\subsubsection{Varsayımlar}

- Her odanın temizliği 20 dk. sürmektedir. Bu süreye temizlik için hazırlık zamanı da dâhildir.

- Tüm odaların $\mathrm{m}^{2}$ 'leri arasındaki fark çok az olduğunda tüm odaların temizlik süreleri eşit kabul edilmiştir. 
- Oda temizliği başladığında yarım bırakılmadan bitirilmelidir, başka vardiya veya güne sarkmamalıdır.

- Bir odanın temizliği bir personel tarafından yapılmalıdır.

\subsubsection{Parametreler}

$\begin{array}{ll}i \text { : Personel indeksi, } & i=1,2, \ldots, n . \\ j: \text { Gün indeksi, } & j=1,2, \ldots, m . \\ k \text { : Vardiya indeksi } & k=1,2, \ldots, v \\ l: \text { Oda İndeksi } & l=1,2, \ldots, p \\ n \text { : İşletmedeki çalışan sayısı } & n=70 \\ m \text { : Gün sayısı } & m=31 \\ v: \text { Vardiya sayısı } & v=3 \\ p: \text { Oda sayısı } & p=58\end{array}$

\subsubsection{Karar Değişkenleri}

$\boldsymbol{X}_{i j k l}=\left\{\begin{array}{cc}1, & \text { i.personel } j . \text { gündeki } k . \text { vardiyada, }, \text {. odaya atanırsa } \\ 0, & \text { diğer durumlarda }\end{array}\right.$

$\boldsymbol{h}_{i j}=\left\{\begin{array}{c}1, i . \text { personel } j . \text { günde izinli ise } \\ 0, \quad \text { diğer durumlarda }\end{array}\right.$

\subsubsection{Kisitlar}

- Temizlenmesi gereken toplam 58 oda vardır. $(i=1,2, \ldots, 58)$

- Bu odaların içinden sabah vardiyasında temizlenmesi gereken 18 oda vardır. $(i=1,2, \ldots, 18)$

- Bu odaların içinden öğle vardiyasında temizlenmesi gereken 19 oda vardır. $(i=19,20, \ldots, 37)$

- Bu odaların içinden gece vardiyasında temizlenmesi gereken 21 oda vardır. $(i=38,39, \ldots, 58)$

- Gece temizlenecek odaları mümkün olduğu kadarıyla 4. 5. dereceye sahip tecrübeli personeller tarafindan temizlemelidir. (Genellikle gece vardiyasında olması beklenmektedir.) 
1.Klsıt: Her bir vardiyada temizlenmesi zorunlu odaların personele atanma kısıtları:

$\sum_{i=1}^{n} X_{i j 1 l}=1$

$$
\begin{array}{lll}
\sum_{i=1}^{n} X_{i j 1 l}=1 & j=1,2,3, \ldots, m & l=1,2, \ldots, 18 \\
\sum_{i=1}^{n} X_{i j 2 l}=1 & j=1,2,3, \ldots, m & l=19,20, \ldots, 37 \\
\sum_{i=1}^{n} X_{i j 3 l}=1 & j=1,2,3, \ldots, m & l=38,39, \ldots, 58
\end{array}
$$$$
\sum_{i=1}^{n} X_{i j 3 l}=1
$$

2.Kısıt: Fazladan atama yapılmaması için yazılmış kısıtlar (Aynı zamanda birden fazla yere atama yapılmaması için yazılan kısıt):

$$
\begin{array}{llll}
X_{i j 1 l}=0 & i=1,2,3, \ldots, n & j=1,2,3, \ldots, m & l=19,20, \ldots, 58 \\
X_{i j 2 l}=0 & i=1,2,3, \ldots, n & j=1,2,3, \ldots, m & l=1,2, \ldots, 18,38,39, \ldots, 58 \\
X_{i j 3 l}=0 & i=1,2,3, \ldots, n & j=1,2,3, \ldots, m & l=1,2, \ldots, 37
\end{array}
$$

3.Kısıt: Görevlilerin atandıkları günlerde sadece tek vardiyada çalışmalarını karşılayan kısıt:

$\sum_{k=1}^{v} \sum_{l=1}^{58} X_{i j k l} \leq 1 \quad i=1,2,3, \ldots, n \quad j=1,2, \ldots, m$

4.Kısıt: Eğer bir görevli herhangi bir gün izinli ise o gün çalışmaması için yazılmış kısıt:

$\sum_{k=1}^{v} \sum_{l=1}^{58} X_{i j k l} \leq 1-h_{i j} \quad i=1,2,3, \ldots, n \quad j=1,2, \ldots, m$

5.Kısıt: Her görevli ardı ardına en fazla 6 gün çalışmalıdır koşulunu sağlayan kısıt:

$h_{i j}+h_{i j+1}+h_{i j+2}+h_{i j+3}+h_{i j+4}+h_{i j+5}+h_{i j+6} \geq 1 \quad i=1,2,3, \ldots, n \quad j=1,2, \ldots, m$

6.Kısıt: Her görevli akşam vardiyasında çalıştıysa ertesi günün sabah vardiyasında çalışmamalı koşulunu sağlayan kısıt (Gece vardiyası sonrası dinlenmelerini sağlayan kısıt):

$\sum_{l=1}^{58} X_{i j 3 l}+X_{i j+11 l}+X_{i j+12 l} \leq 1 \quad i=1,2,3, \ldots, n \quad j=1,2, \ldots, 30$

7.Kısıt: Her bir görevli gece vardiyasında çalıştıysa ertesi gün sabah ve akşam vardiyalarında çalışmamalı koşulunu sağlayan kısıt: 
$\sum_{l=1}^{58} X_{i j 2 l}+X_{i j+11 l} \leq 1 \quad i=1,2,3, \ldots, n \quad j=1,2, \ldots, 30$

8.Klsıt: 1 2.3.4. kıdemler her hafta 1 gün izinli olmalıdır koşulunu sağlayan kısıt:

$\sum_{j=1}^{7} h_{i j}=1 \quad i=1,2,3, \ldots, 59$

$\sum_{j=8}^{14} h_{i j}=1 \quad i=1,2,3, \ldots, 59$

$\sum_{j=15}^{21} h_{i j}=1 \quad i=1,2,3, \ldots, 59$

$\sum_{j=22}^{28} h_{i j}=1 \quad i=1,2,3, \ldots, 59$

9.Kısıt: 5. kıdeme sahip görevliler her hafta 2 gün izinli olmalıdır koşulunu sağlayan kısıt:

$\sum_{j=1}^{7} h_{i j}=2 \quad i=60, \ldots 70$

$\sum_{j=8}^{14} h_{i j}=2 \quad i=60, \ldots 70$

$\sum_{j=15}^{21} h_{i j}=2 \quad i=60, \ldots 70$

$\sum_{j=22}^{28} h_{i j}=2 \quad i=60, \ldots 70$

10.Kısıt: 4. kıdeme sahip görevliler en fazla 25 gün çalışmalıdır koşulunu sağlayan kısıt:

$\sum_{j=1}^{m} \sum_{k=1}^{v} \sum_{l=1}^{58} X_{i j k l} \leq 25 \quad i=45,46, \ldots, 59$

11.Kısıt: 4. kıdeme sahip görevliler en az 24 gün çalışmalıdır koşulunu sağlayan kısıt:

$\sum_{j=1}^{m} \sum_{k=1}^{v} \sum_{l=1}^{58} X_{i j k l} \geq 24 \quad i=45,46, \ldots, 59$

\subsubsection{Hedef Kisıtları}

Hedef 1: Gece vardiyasında mümkün olduğu kadar 4. ve 5. kıdeme sahip görevliler çalışmalıdır:

$\sum_{j=1}^{m} \sum_{l=1}^{58} X_{i j 3 l}-d 1_{i}^{+}+d 1_{i}^{-}=0 \quad i=1,2,3, \ldots, 44$

Hedef 2: 5.kıdeme sahip görevliler mümkün olduğu kadar aylık planda toplam 23 gün çalışmalıdır:

$\sum_{j=1}^{m} \sum_{k=1}^{v} \sum_{l=1}^{58} X_{i j k l}-d 2_{i}^{+}+d 2_{i}^{-}=23 \quad i=60,61,62, \ldots, 70$ 
Hedef 3: 1.2.3. kıdeme sahip görevliler mümkün olduğu kadar aylık planda toplam 26 gün çalışmalıdır:

$\sum_{j=1}^{m} \sum_{k=1}^{v} \sum_{l=1}^{58} X_{i j k l}-d 4_{i}^{+}+d 4_{i}^{-}=26 \quad i=1,2,3, \ldots, 44$

\subsubsection{Amaç Fonksiyonu}

$\operatorname{Min} Z=\sum_{i=1}^{n} d 1_{i}^{+}+d 1_{i}^{-}+d 2_{i}^{+}+d 2_{i}^{-}+d 3_{i}^{+}+d 3_{i}^{-}+d 4_{i}^{+}+d 4_{i}^{-}$

Modelin çözümünde “Intel (R) Core (TM) i7-2630QM CPU@2.00 GH” işlemcisi olan, 16 GB belleği ve Windows 10 işletim sistemine sahip bir bilgisayar kullanılmıştır. İlgili verilerin girilmesiyle model ILOG CPLEX Studio IDE programında yazılmış ve CPLEX çözücüsü ile çözülmüştür.

\subsection{Bulgular}

Personellerin vardiyalara göre temizlemesi gereken odaların sayısı ve toplam temizlenen oda sayıları Tablo 2'de verilmiştir. Çizelgenin daha kolay anlaşılabilmesi için kısaltmalar kullanılmıştır. Kullanılan kısaltmalara göre; $\mathrm{P}$ harfi personelin numarasını, S harfi personelin sabah vardiyalarında temizlediği oda sayısını, Ö harfi personelin öğle vardiyalarında temizlediği oda sayısını, G harfi personelin gece vardiyalarında temizlediği oda sayısını ve T harfi ise personelin farklı vardiyalarda temizlediği toplam oda sayısını göstermektedir.

Problemin çözümünden elde edilen sonuca bakıldığında dengeli bir atama yapıldığ görülmektedir. Tecrübeli personelin (5. Derece) gece vardiyalarına atanması ve diğer personellerden (1., 2., 3. ve 4. Derece) daha az iş günü çalışması kısıtlarının sağlandığı görülmektedir. Ayrıca, 4. Derece personelin ve 1., 2. ve 3. Derece personellerin aylık çalışmaları gereken işgünleri de düzenli bir şekilde gerçekleştirilmiştir. Tablo 2'de gözlemlenen sonuçlara göre atamalar dengeli olmuştur. Elde edilen sonuçlar mevcut durumdaki çizelgeleme sonuçlarına göre iyileşme göstermiştir. Mevcut durumdaki çizelgelemeye göre, personel ataması dengeli bir şekilde sağlanmazken yeni sonuçlarla bu problemin ortadan kalktığı görünmektedir. 
Tablo 2. Son Atama

\begin{tabular}{|c|c|c|c|c|c|c|c|c|c|c|c|c|c|c|}
\hline $\mathbf{P}$ & $\mathbf{S}$ & Ö & $\mathbf{G}$ & $\mathbf{T}$ & $\mathbf{P}$ & $\mathbf{S}$ & Ö & G & $\mathbf{T}$ & $\mathbf{P}$ & $\mathbf{S}$ & Ö & $\mathbf{G}$ & $\mathbf{T}$ \\
\hline 1 & 13 & 11 & 2 & 26 & 25 & 13 & 14 & 0 & 27 & 49 & 0 & 0 & 25 & 25 \\
\hline 2 & 10 & 16 & 0 & 26 & 26 & 13 & 12 & 1 & 26 & 50 & 0 & 0 & 25 & 25 \\
\hline 3 & 19 & 7 & 1 & 27 & 27 & 16 & 9 & 1 & 26 & 51 & 0 & 0 & 25 & 25 \\
\hline 4 & 6 & 21 & 0 & 27 & 28 & 7 & 19 & 0 & 26 & 52 & 0 & 0 & 25 & 25 \\
\hline 5 & 8 & 19 & 0 & 27 & 29 & 17 & 10 & 0 & 27 & 53 & 0 & 0 & 25 & 25 \\
\hline 6 & 12 & 14 & 0 & 26 & 30 & 19 & 7 & 0 & 26 & 54 & 0 & 0 & 25 & 25 \\
\hline 7 & 15 & 12 & 0 & 27 & 31 & 7 & 19 & 1 & 27 & 55 & 0 & 0 & 25 & 25 \\
\hline 8 & 10 & 17 & 0 & 27 & 32 & 14 & 12 & 0 & 26 & 56 & 0 & 0 & 25 & 25 \\
\hline 9 & 12 & 13 & 1 & 26 & 33 & 10 & 17 & 0 & 27 & 57 & 0 & 0 & 24 & 24 \\
\hline 10 & 15 & 12 & 0 & 27 & 34 & 8 & 15 & 3 & 26 & 58 & 0 & 0 & 25 & 25 \\
\hline 11 & 6 & 18 & 2 & 26 & 35 & 7 & 19 & 1 & 27 & 59 & 0 & 0 & 25 & 25 \\
\hline 12 & 8 & 18 & 0 & 26 & 36 & 20 & 6 & 0 & 26 & 60 & 0 & 0 & 23 & 23 \\
\hline 13 & 7 & 19 & 1 & 27 & 37 & 25 & 2 & 0 & 27 & 61 & 0 & 0 & 23 & 23 \\
\hline 14 & 10 & 17 & 0 & 27 & 38 & 18 & 7 & 2 & 27 & 62 & 0 & 0 & 23 & 23 \\
\hline 15 & 8 & 15 & 3 & 26 & 39 & 12 & 15 & 0 & 27 & 63 & 0 & 0 & 23 & 23 \\
\hline 16 & 13 & 14 & 0 & 27 & 40 & 8 & 18 & 0 & 26 & 64 & 0 & 0 & 23 & 23 \\
\hline 17 & 12 & 15 & 0 & 27 & 41 & 22 & 3 & 1 & 26 & 65 & 0 & 0 & 23 & 23 \\
\hline 18 & 16 & 11 & 0 & 27 & 42 & 7 & 20 & 0 & 27 & 66 & 0 & 0 & 23 & 23 \\
\hline 19 & 11 & 16 & 0 & 27 & 43 & 21 & 6 & 0 & 27 & 67 & 0 & 0 & 23 & 23 \\
\hline 20 & 16 & 8 & 2 & 26 & 44 & 16 & 10 & 0 & 26 & 68 & 0 & 0 & 23 & 23 \\
\hline 21 & 7 & 20 & 0 & 27 & 45 & 0 & 0 & 25 & 25 & 69 & 0 & 0 & 23 & 23 \\
\hline 22 & 15 & 11 & 1 & 27 & 46 & 0 & 0 & 25 & 25 & 70 & 0 & 0 & 23 & 23 \\
\hline 23 & 10 & 17 & 0 & 27 & 47 & 0 & 0 & 25 & 25 & & & & & \\
\hline 24 & 18 & 8 & 0 & 26 & 48 & 0 & 0 & 25 & 25 & & & & & \\
\hline
\end{tabular}

\section{Sonuç ve Değerlendirme}

$\mathrm{Bu}$ çalışmada bir üniversite hastanesindeki temizlik personellerinin, farklı hedefleri göz ardı etmeden çalışma çizelgeleri planlamıştır. Çizelgeleme 70 personelin bir aylık çalışmalarını kapsamaktadır. Bu çalışma yapılmadan önce, mevcut iş çizelgelemesinin el ile yapıldığı göz önüne alındığında, çalışmanın faydası bir kez daha ortaya konulmuştur. Çalışan sayısının fazlalığı ve temizlenmesi gereken oda sayıları düşünülünce, problem boyutunun büyük olması çizelgeleme işinin el ile yapılmasını oldukça zorlaştırmaktadır. Ayrıca bu işlemin el ile yapılması iş dağılımdaki adaleti tehlikeye atmaktadır. Kullanılan bu matematiksel modellerle hem çizelgelerinin hazırlanma süreci kısalmakta hem de kaliteli çizelgeler elde edilmektedir. Çalışmada geliştirilen matematiksel modelde çalışanların istekleri mümkün olduğu kadarıyla yerine getirilmiştir. Gerçekleştirilmesi gereken 
hedefler ve personelin isteklerini en az sapma ile sağlamak için hedef programlama tekniği kullanılmıştır.

Bundan sonraki çalışmalarda kurulan modeller sadece hastane ortamında değil daha birçok sektörde uygulanıp kullanılabilir. Bu çalışmadaki oda sayıları, personel sayıları, personel istekleri ve bunun gibi her türlü unsur artırılarak daha geniş çaplı çizelgeler yapılabilir. Kullanılacak modellerin büyüklüğüne göre meta sezgisel yöntemlerden faydalanılabilir.

\section{Kaynaklar}

Azaiez, M.N., ve Al-Sharif, S.S., (2005), A 0-1 goal programming model for nurse scheduling, Computers and Operations Research, 32, 491-507.

Bağ, N., Özdemir, M., ve Eren, T., (2012), 0-1 Hedef Programlama ve ANP Yöntemi ile Hemşire Çizelgeleme Problemi Çözümü. International Journal of Engineering Research and Development, 1,2-6.

Bard, J.F., Binici, C. ve De Silva, A.H., (2003), Staff scheduling at the United States Postal Service, Computers and Operations Research, 30, 745-771.

Bektur, G. ve Hasgül, S., (2013), Kıdem seviyelerine göre işgücü çizelgeleme problemi: Hizmet sektöründe bir uygulama, Afyon Kocatepe Üniversitesi İktisadi ve İdari ve Bilimler Fakültesi Dergisi, 15, 385-402.

Bergh, J.V., Beliën, J., Bruecker, P., Demeulemeester, E. ve Boeck, L., (2013), Personnel scheduling: A literature review, European Journal of Operations Research, 226, 367-385.

Charnes, A. ve Cooper, W.W., (1977), Goal programming and multipleobjective optimizations, European Journal of Operational Research I, 39-54.

Chu, S. C. K., (2007), Generating, scheduling and rostering of shift crew-duties: Applications at the Hong Kong International Airport, European Journal of Operational Research, 177, 1764-1778.

Ciritoğlu, C., Akgün, S., Varlı, E., Eren, T., (2017) Kırıkkale Üniversitesi Güvenlik Görevlileri İçin Vardiya Çizelgeleme Problemine Bir Çözüm Önerisi, Uluslararası Mühendislik Araştırma ve Geliştirme Dergisi, 9 (2) 1-23.

Corominas, A., Lusa, A., ve Pastor, R., (2004), Planning annualised hours with a finite set of weekly working hours and joint holidays, Annals of Operations Research, 128, 217-233.

Corominas, A., Lusa, A., ve Pastor, R., (2007), Using a MILP model to establish a framework for an annualised hours agreement, European Journal of Operational Research, 177, 1495-1506.

Çetin, E.İ., Kuruüzüm, A. ve Irmak, S., (2008), Ekip Çizelgeleme Probleminin Küme Bölme Modeli ile Çözümü, Havacılık ve Uzay Teknolojileri Dergisi, 3, 47-54.

Dantzig, B. G., Letter to the Editor-A Comment on Edie's Traffic Delays at Toll Booths, Operations Research, 2, 339-341, 1954.

De Matta, R. ve Peters, E., (2009), Developing work schedules for an inter-city transit system wit hmultiple driver types and fleet types, European Journal of Operational Research, 192, 852-865.

Edie, L. C., (1954), Traffic delays at toll booths, Operations Research, 2, 107-138.

Ernst, A.T., Jiang, H., Krishnamoorthy, M., ve Sier, D., (2004), Staff scheduling and rostering: a review of applications, methods and models, European Journal of Operations Research, 153, 3-27.

Firat, M. ve Hurkens, C.A.J., (2011), An improved MIP-based approach for a multi-skill workforce scheduling problem, Journal of Scheduling, 15, 363-380.

Güneş, A., Kahvecioğlu, A. ve Tuncel, H., (2005), Askeri nöbet çizelgelerinin genetik algoritma kullanılarak en iyilenmesi, Elektrik-Elektronik- Bilgisayar Mühendisliği 11 'inci Ulusal Kongresi ve Fuarı, İstanbul, 470-474.

Horn, M., Jiang, H.ve Kilby, P., (2007), Scheduling patrol boats and crews for the Royal Australian Navy, Journal of the Operational Research Society, 58, 1284-1293.

Hung-Tso, L., Yen-Ting, C., Tsung-Yu, C. ve Yi-Chun, L., (2012), Crew rostering with multiple goals: an empirical study, Computers and Industrial Engineering, 63, 483-493.

Kassa, B. A. ve Tizazu, A. E., (2013), Personnel scheduling using an integer programming model- an application at Avanti Blue-Nile Hotels, Springer Plus, 2:333, 1-7. 
Labidi, M., Mrad, M., Gharbi, A., ve Louly, M.A., (2014), Scheduling IT Staff at a Bank: A Mathematical Programming Approach, The Scientific World Journal, Article ID 768374.

Lezaun, M., Perez, G., ve De La Maza, E. S., (2006), Crew rostering problem in a public transport company, Journal of the Operational Research Society, 57, 1173-1179.

Lezaun, M., Perez, G., ve De La Maza, E. S., (2007), Rostering in a rail passenger carrier, Journal of Scheduling, 10, 245-254.

Lezaun, M., Perez, G., ve De La Maza, E. S., (2010), Staff rostering for the station personnel of a railway company, Journal of the Operational Research Society, 61, 1104-1111.

Li, J., Burke, E.K., Curtois, T., Petrovic, S. ve Rong, Q., (2012), The falling tide algorithm: a new multiobjective approach for complex workforce scheduling, Omega, 40, 283-293.

Louly, M.A., (2013), A goal programming model for staff scheduling at a telecommunications center, Journal of Mathematical Modelling and Algorithms in Operations Research, 12, 167-178.

Özder, E. H., (2015), Tedarikçi seçiminde analitik ă̆ süreci ve hedef programlama tekniklerinin entegrasyonu: Örnek olay çalışması, Yüksek Lisans Tezi, Kırıkkale Üniversitesi, Endüstri Mühendisliği Bölümü, Yöneylem Araştırması Anabilim Dalı.

Öztürkoğlu, Y. ve Çalışkan, F., (2014), Hemşire Çizelgelemesinde Esnek Vardiya Planlaması ve Hastane Uygulamas1, Dokuz Eylül Üniversitesi Sosyal Bilimler Enstitüsü Dergisi, 16, 115-133, 2014.

Romero, C., (2010), Extended lexicographic goal programming: A unifying approach, Omega, The International Journal of Management Science, 29: 63-71.

Rönnberg, E. ve Larsson, T., (2010), Automating the self-scheduling process of nurses in Swedish healthcare: a pilot study, Health Care Management Science, 13, 35-53.

Sinreich, D. ve Jabali, O., (2007), Staggered workshifts: a way to downsize and restructure an emergency department workforce yet maintain current operational performance, Health Care Management Science, 10, 293-308.

Sungur, B., (2008), Bir güzellik salonunun tur çizelgeleme problemi için karma tamsayılı hedef programlama modelinin geliştirilmesi, İstanbul Üniversitesi İşletme Fakültesi Dergisi, 37, 49-64.

Şahiner M., Aktürk M. S., Ünlüsoy S., Bedir N., Varlı E., Eren T., (2017), Hemşire Çizelgeleme İçin Model Önerisi: Örnek Uygulama, Trakya Üniversitesi İktisadi ve İdari Bilimler Fakültesi Dergisi, 10 (2), 185197.

Tamiz, M. ve Jones, D.F., (1997), Interactive Framework For Investigation Of Goal Programming Models: Theory And Practice, Journal of Multi-Criteria Decision Analysis, 6: 52-60.

Tamiz, M., Mirrazavi, S.K. ve Jones, D.F., (1999), Extensions of Pareto Efficiency Analysis to Integer Goal Programming, Omega, 27, (2): 179-188.

Thompson, G. M. ve Pullman, M. E., (2007), Scheduling workforce relief breaks in advance versus in realtime, European Journal of Operational Research, 181, 139-155.

Todovic, D., Makajic-Nikolic, D., Kostic-Stankovic, M., ve Martic, M., (2015), Police officer scheduling using goal programming, Policing: An International Journal of Police Strategies and Management, 38, 295313.

Topaloğlu, S., (2006), A multi-objective programming model for scheduling emergency medicine residents, Computers and Industrial Engineering, 51, 375-388.

Trilling, L., Guinet, A., ve Le Magny, D., (2006), Nurse scheduling using integer linear programming and constraint programming, 12th IFAC International Symposium, Elsevier, 3,651-656.

Tsai, C.C. ve. Li, S.H.A, (2009), A two-stage modeling with genetic algorithms for the nurse scheduling problem, Expert Systems with Applications, 36, 9506-9512.

Ünal, F.M. ve Eren, T., (2016), Hedef Programlama ile Nöbet Çizelgeleme Probleminin Çözümü, Akademik Platform Mühendislik ve Fen Bilimleri Dergisi, 4 (1), 28-37.

Varlı, E., Eren, T., Gençer, M. A., ve Çetin, S., (2016), Ankara Metrosu M1 Hattındaki Vatmanların Vardiya Saatlerinin Çizelgelenmesi, 3.Uluslararası Raylı Sistemler Mühendisliği Sempozyumu-Karabük.

Varlı, E., Eren, T., (2017), Hemşire Çizelgeleme Problemi Ve Hastanede Bir Uygulama, Akademik Platform Mühendislik ve Fen Bilimleri Dergisi, 5 (1), 34-40.

Varlı, E., Ergişi, B., Eren, T., (2017), Özel Kısıtlı Hemşire Çizelgeleme Problemi: Hedef Programlama Yaklaşım1, Erciyes Üniversitesi İktisadi ve İdari Bilimler Fakültesi Dergisi, (0) 49, 189-206.

Yunes, T. H., Moura, A. V., ve De Souza, C. C., (2005), Hybrid column generation approaches for urban transit crew management problems, Transportation Science, 39, 273-288.

Zolfaghari, S., Quan, V., El-Bouri, A. ve Khashayardoust, M., (2010), Application of a genetic algorithm to staff scheduling in retail sector, International Journal of Industrial and Systems Engineering, 5, 20-47. 